\title{
Exacerbation of Chronic Obstructive Pulmonary Disease
}

\author{
Xianghui Zhou $\cdot$ Qingling Li $\cdot$ Xincan Zhou
}

Published online: 23 May 2015

(c) Springer Science+Business Media New York 2015

\begin{abstract}
Chronic obstructive pulmonary disease (COPD) is a disease with high prevalence and substantial associated economical burden. A significant determinant of quality of life, long-term survival, and health care costs is an acute exacerbation of COPD. Acute exacerbations are provoked by respiratory viruses, altered airway microbiome, and environmental factors. The current treatment options are limited. In order to develop specific therapeutic measures, it is important to understand how acute exacerbations evolve. This review focuses on pathophysiology of stable and exacerbated COPD.
\end{abstract}

Keywords COPD - Exacerbation - Virus · Bacteria · Innate immunity $\cdot$ Inflammation $\cdot$ Review

\section{Introduction}

High prevalence and substantial associated economical burden set chronic obstructive pulmonary disease (COPD) apart from other respiratory diseases. Worldwide, 64 million people were estimated by World Health Organization in 2004 to have COPD. The estimates of the prevalence of this disease in different countries range between 8 and $12 \%$ [1]. In China, the prevalence of COPD was estimated at $8.2 \%$ by a recent study [2]. Being a sixth leading cause of deaths in the 1990s, COPD now ranks among top three leading causes of death worldwide, with more than

X. Zhou $\cdot$ Q. Li $(\bowtie) \cdot X$. Zhou

Department of Respiratory Medicine, The First Xuzhou People's

Hospital, 19 Zhongshan North Road, Xuzhou 221003, Jiangsu,

China

e-mail: dr-liqingling@163.com
3 million deaths in 2012. The mortality rates of this disease are surpassed only by ischemic heart disease and stroke (Fig. 1). Furthermore, World Health Organization estimates that the overwhelming majority (almost $90 \%$ ) of COPD-associated deaths occur in developing countries due to insufficient prevention and control. It is estimated that prevalence of COPD will increase within the next 10 years, while mortality will remain at the current rate.

COPD is substantial burden to both patients and the health care system. Patients, especially those with severe disease, can be limited in their daily activities because of dyspnoea, cough, and fatigue. This constant handicap is further worsened during acute exacerbations of this disease. COPD exacerbations deteriorate patients' quality of life and survival [3-6]. A significant proportion of patients with COPD experiences frequent exacerbations ("frequent exacerbators") [7]. Frequent exacerbations are associated with increased likelihood of COPD-associated death [8]. Furthermore, COPD exacerbations are a very significant contributor to COPD-associated health care costs, mostly due to hospitalizations. Thus, the costs of COPD hospitalizations were estimated to be $\$ 11.9$ billion in the USA in 2006 , with an average cost of hospitalization of $\$ 9545$ per patient [9]. In China, the cost of inpatient care for acute exacerbation of COPD has also been estimated high [10]. Given that COPD exacerbations are a significant contributor to morbidity and mortality associated with this disease, and cause substantial financial costs, mainly due to hospitalization, it is crucial to better understand the factors leading to COPD exacerbations to be able to develop effective measures to prevent and/or treat these exacerbations. The present review will focus on current understanding of the pathophysiology of COPD exacerbations, and current and potential preventive or therapeutic measures. 


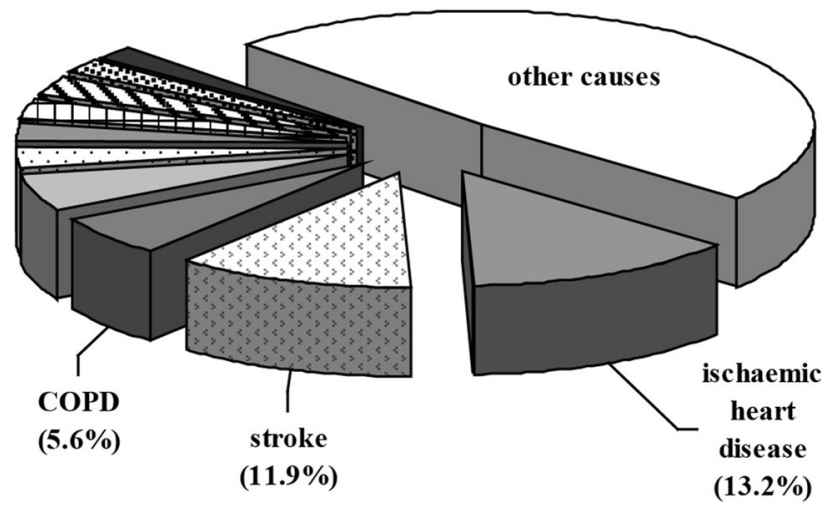

Fig. 1 The top 10 causes of death worldwide (World Health Care data). The causes of death are shown as percentages. The COPDassociated deaths account for $5.6 \%$ worldwide, making COPD among the top three causes of death. Other causes of death showed without labels are lower respiratory infections (5.5\%), lung cancers $(2.9 \%)$, HIV/AIDS $(2.7 \%)$, diabetes mellitus $(2.7 \%)$, diarrheal diseases $(2.7 \%)$, road injuries $(2.2 \%)$, and hypertensive heart disease ( $2 \%)$. Other causes account for $48.6 \%$ of deaths worldwide

\section{Pathophysiology of COPD}

The Global Initiative for Chronic Obstructive Lung Disease (GOLD) defines COPD as a disease that is "usually progressive and associated with an enhanced chronic inflammatory response in the airways and the lung to noxious particles or gases" [11]. These noxious particles or gases are inhaled with cigarette smoke or smoke from burning biomass fuel, the latter being more relevant for low-income countries [12]. Anatomically, the abnormal processes in the airways of patients with COPD develop as poorly reversible or irreversible airway obstruction, or emphysema (rupture of the inner walls of alveolar sacs with creation of larger air spaces with trapped air), or a combination of both. The disease is frequently accompanied by mucus hypersecretion that leads to productive cough and may impair bacterial clearances.

These abnormalities are a result of direct damaging effects of inhaled particles and gases, and subsequent cellular inflammatory processes in the airway. Inflammation in the airways of these patients is excessive and persists even after smoke cessation. Cellular inflammation is characterized by excessive numbers of macrophages, $\mathrm{T}$ and $\mathrm{B}$ lymphocytes, and neutrophils in airway lumen [13]. Airway epithelial cells are also prominently involved in perpetuation and amplification of airway inflammation in COPD, as demonstrated by their pro-inflammatory phenotype under basal culture conditions in the in vitro experiments [14]. Airway epithelial cells and macrophages are the cells that are constantly present in the airways, and are, probably, the first responders to exposure to cigarette smoke or smoke from biomass fuels. Cigarette smoke contains more than 4000 compounds, including carcinogens, oxidants, toxic metals, and even bacterial endotoxins [15-17] These compounds have been shown in cell and animal studies to cause inflammatory responses, cell apoptosis and necrosis, and dysregulation of innate immunity. Thus, numerous studies demonstrate that cigarette smoke stimulates production of inflammatory chemokines from airway epithelial cells. Said chemokines attract haemopoetic inflammatory cells (e.g., neutrophils) which are normally not present in the airways and are capable of causing extensive damaging effects. It is plausible that inflammatory processes initiated by smoke inhalation are further perpetuated and amplified by the responses of cells resident to the airways (e.g., airway epithelial cells, macrophages, lymphocytes, fibroblasts). As "biomass," one refers to organic materials (wood, charcoal, dried animal dung fuel, etc.) that are used for cooking or heating of a dwelling [18]. The biomass combustion efficiency is lower than that of energy sources typically used in the Western world (e.g., coal or natural gas). The burning of biomass releases gases and particulate matters, including carbon monoxide, pollutants, oxidants, cancerogens, etc. [19]. These exert damaging effects on airway cells that are similar to those by cigarette smoke [20, 21].

It is possible that the damaging effects are especially extensive in susceptible individuals, which is demonstrated by the fact that not all smokers develop COPD. Therefore, besides the exposure to damaging compounds in cigarette or biofuel smoke, it may also take additional environmental or genetic factors to develop COPD [22].

Patients with COPD often harbor increased numbers of commensal or pathogenic microorganisms in their airways. The total population of microorganisms that reside in a specific area (e.g., the airways) is called microbiome. The studies of COPD microbiome have only recently commenced, and therefore, we presently have only a limited knowledge of potential microbiome abnormalities [23]. Traditionally, microorganisms have been identified via culturing, which led to believe that normal human airways are sterile. However, newer microbiome studies complement traditional culturing techniques with molecular biology tools, such as PCR or sequencing, and demonstrate that even healthy individuals harbor some non-pathogenic microorganisms in their airways. In contrast, patients with COPD demonstrate either elevated numbers of the microorganisms found in healthy individuals or microorganisms not typically present in healthy airway microbiome. Among different microorganisms typical for COPD airways are Haemophilus influenzae, Streptococcus pneumoniae, Moraxella catarrhalis, and, in more severe patients, Pseudomonas aeruginosa (Table 1). It is suspected that the altered microbiome may also be a significant contributor to 
Table 1 Microorganisms found in the upper and lower airways of patients with COPD

\begin{tabular}{|c|c|c|}
\hline Microorganisms & Study & Disease state \\
\hline $\begin{array}{l}\text { Lactobacillus spp., Streptococcus spp., Pseudomonas spp., Neisseria spp., Prevotella } \\
\text { spp., Veillonella spp. }\end{array}$ & Park et al. $[52]^{\mathrm{a}}$ & $\begin{array}{l}\text { Stable disease, Gold stage I-III } \\
\text { (predominantly, I and II) }\end{array}$ \\
\hline $\begin{array}{l}\text { Haemophilus influenzae, Streptococcus pneumoniae, Pseudomonas aeruginosa, } \\
\text { Klebsiella spp., Moraxella catarrhalis, Pseudomonas fluorescens }\end{array}$ & $\begin{array}{l}\text { Huang et al. } \\
{[28]^{\mathrm{b}}}\end{array}$ & Exacerbation, Gold stage I-III \\
\hline $\begin{array}{l}\text { Genera Afipia, Brevundimonas, Curvibacter, Moraxella, Neisseria, Undibacterium, } \\
\text { Corynebacterium, Capnocytophaga, Leptolyngbia; Pseudomonas aeruginosa }\end{array}$ & $\begin{array}{l}\text { Zakharkina } \\
\text { et al. }[53]^{\mathrm{c}}\end{array}$ & Stable, Gold stage I-III \\
\hline $\begin{array}{l}\text { Genera Proteobacteria, Bacteroidia, Actinobacteria, Firmicutes, Streptococcus, } \\
\text { Prevotella Fusobacterium, Neisseria, Moraxella, Haemophilus, and Acinetobacter }\end{array}$ & $\begin{array}{l}\text { Cabrera-Rubio } \\
\text { et al. }[54]^{\text {bc }}\end{array}$ & $\begin{array}{l}\text { Stable, Gold stage I-III } \\
\text { (predominantly, I and II) }\end{array}$ \\
\hline $\begin{array}{l}\text { Families Acidimicrobiaceae, Burkholderiaceae, Campylobacteraceae, } \\
\text { Caulobacteraceae, Chloroplasts, Crenotrichaceae, Desulfomicrobiaceae, } \\
\text { Enterobacteriaceae, Helicobacteraceae Leptospiraceae, Moraxellaceae, } \\
\text { Nitrosomonadaceae, Peptococc/Acidaminococc, Pirellulae, Piscirickettsiaceae, } \\
\text { Pseudomonadaceae, Sphingobacteriaceae, Thermoactinomycetaceae, } \\
\text { Thermodesulfobacteriaceae, Xanthomonadaceae, Xiphinematobacteraceae }\end{array}$ & $\begin{array}{l}\text { Huang et al. } \\
{[55]^{\mathrm{a}}}\end{array}$ & $\begin{array}{l}\text { Severe exacerbation (intubated } \\
\text { patients) }\end{array}$ \\
\hline \multicolumn{3}{|l|}{ a Oropharyngeal swabs or endotracheal aspirates (upper airways) } \\
\hline \multicolumn{3}{|l|}{ b Sputum or bronchial aspirate (central airways) } \\
\hline c Broncho-alveolar lavage (lower airways) & & \\
\hline
\end{tabular}

perpetuation and amplification of airway inflammation in COPD [23].

In the past, atopic asthma was seen as a disorder very different from COPD, with the research emphasized Th2and eosinophil-driven inflammatory mechanisms in atopic asthma and neutrophil-driven inflammation in COPD. However, it is increasingly recognized that asthma and COPD may be part of a long continuum of respiratory diseases with many disorders, such as atopic asthma in smokers or allergies in patients with COPD. In latter patients, the inflammatory processes in the airways may be associated with eosinophilia [24].

Non-smokers can also develop COPD [25-27]. The disease development is of unclear pathogenesis in these patients and may involve genetic and/or environmental factors, including second-hand exposure to cigarette smoke. Genetic factors predisposing to COPD have not been revealed, possibly, due to multigenetic nature of abnormalities in the airways (e.g., antioxidant or inflammatory genes, genes encoding proteolytic enzymes, etc.). There is, however, mutation of the gene SERPINAl, that encodes alpha- 1 antitrypsin, that causes pathological abnormalities in the lung similar to those in emphysema. However, this genetic disorder is typically classified separately from typical COPD.

\section{Acute Exacerbation of COPD}

The consensus definition of acute exacerbation of COPD is as follows: "an acute event characterized by a worsening of the patient's respiratory symptoms that is beyond normal day-to-day variations and leads to a change in medication" [11]. As noted above, not only do COPD exacerbations negatively affect the quality of life of these patients, the exacerbations also substantially increase risk of pre-mature death and cause substantial financial burden to the health care system due to hospitalization and need for specialized care. The most typical provoking factors for COPD exacerbations are bacterial and viral infections.

As discussed above, patients with COPD are reported to harbor diverse bacteria, often including opportunistic microorganisms, such as $P$. aeruginosa. During exacerbations, the number of these bacteria (very commonly, $H$. influenzae) increases in many patients, which may be because of the outgrowth of the existing strains or acquisition of the new ones [28]. Bacteria-driven genesis of many COPD exacerbations, especially those with increased sputum purulence, is confirmed by clinical efficacy of antibiotics [29]. Studies further demonstrate that acute exacerbations may be associated with acquisition of new bacterial strains [28, 30], against which the patients do not have specific antibodies [30]. These observations further support etiological role of bacterial infection in acute exacerbation of COPD.

But what leads to acquisition of new strains or outgrowth of the existing strains? Recent research data strongly suggest that the majority of COPD exacerbations are associated with upper respiratory viral infections. First, respiratory viruses are detected in upper and lower airway secretions from patients with COPD in a significant number of acute exacerbations [31, 32]. Second, experimental virus infections of patients with COPD demonstrate a subsequent bacterial outgrowth [33], confirming a causative link 
between upper respiratory virus infections, subsequent bacterial infection, and acute exacerbation of COPD.

It is estimated that viral or bacterial infections or combination of both are responsible from two thirds to three quarters of all COPD exacerbations [11, 34]. The role of respiratory viruses as pathogens provoking the majority is increasingly recognized [35-37]. Owing to clinical availability of multiplex PCR, detection of respiratory viruses has been greatly facilitated in the recent years. Respiratory viruses most commonly detected during acute exacerbations of COPD are human rhinoviruses, respiratory syncytial virus, and influenza virus, while other viruses are detected less frequently (Table 2). Among these viruses, vaccination is available for influenza virus, and there is a monoclonal antibody against respiratory syncytial virus (palivizumab). Influenza vaccination is routinely used in patients with COPD. It has been discussed that a widespread of influenza vaccination in the Western countries decreased detection of this virus during COPD exacerbations [38]. As the cost of palivizumab is very high, the authors of this review are not aware of the use of this drug for COPD. There is neither vaccine nor monoclonal antibodies available against human rhinoviruses. Pivotal role of human rhinoviruses in COPD exacerbations is demonstrated by both epidemiologic studies and by studies on experimental infection. Specifically, it was shown that inoculation of patients with COPD with a low-dose rhinovirus leads to lower airway symptoms typical for COPD exacerbation (breathlessness, cough, increased mucus production, etc.), as well as secondary bacterial infection $[33,39]$. Furthermore, the peak of rhinovirus load in the lower airway secretions precedes the rise in bacterial load [33]. This confirms anecdotal evidence reported by many patients with COPD that they have had an upper respiratory viral infection ("the common cold") several days before developing an acute exacerbation of their disease. Furthermore, in northern regions, the number of acute exacerbations of COPD peaks during fall and winter months [40, 41], which are also the months with the highest prevalence of upper respiratory virus infections [42]. Therefore, efforts should be aimed at developing effective antiviral measures, also against human rhinovirus, to prevent these and secondary bacterial infections, since both appear to precipitate COPD exacerbations.

About one-third of COPD exacerbations are provoked by factors other than bacterial or viral infections. These could be allergies (in patients with pre-existing allergies), environmental factors, stress, or other intrinsic factors. Environmental factors, such as air pollution, are especially relevant for cities with large industrial base, such as many of those in China. The intrinsic factors may play a role in susceptibility of some COPD individuals to frequent exacerbations (the so-called "frequent exacerbators"), although it is also possible that these patients are prone to viral or bacterial infections. Furthermore, poor patient compliance to therapies during stable disease has been shown as a risk factor for exacerbations [43].

\section{Prophylactic and Therapeutic Measures to Prevent or Treat Acute Exacerbation of COPD}

The current armamentarium of prophylactic and therapeutic measures to effectively control COPD exacerbations is limited. As mentioned above, vaccination is currently available only for influenza virus. In addition,

Table 2 Detection of respiratory viruses in lower airway secretions during acute exacerbations of COPD

\begin{tabular}{|c|c|c|}
\hline Respiratory virus & Characteristics & $\begin{array}{l}\text { Reported prevalence in acute } \\
\text { exacerbations }\end{array}$ \\
\hline Human rhinovirus & $\begin{array}{l}\text { Single-stranded positive sense RNA virus that does not cause extensive cytotoxicity. There } \\
\text { are three major species, A, B, and C, that altogether encompass approx. } 150 \text { serotypes }\end{array}$ & $\begin{array}{l}13.7-19.7 \%[31] ; 14.8 \% \\
{[13.2-16.5 \%][32]}\end{array}$ \\
\hline $\begin{array}{l}\text { Respiratory } \\
\text { syncytial virus }\end{array}$ & Single-stranded negative sense RNA virus that can cause extensive cytotoxicity & $\begin{array}{l}9.4-14.8 \%[31] ; 9.0 \% \\
{[7.8-10.4 \%][32]}\end{array}$ \\
\hline Influenza & $\begin{array}{l}\text { Single-stranded negative sense RNA virus that can cause extensive cytotoxicity. There are } \\
\text { three major species, A, B, and C. The influenza virus A comprises several serotypes, } \\
\text { including endemic ones }\end{array}$ & $\begin{array}{l}7.1-12.6 \%[31] ; 8.2 \% \\
{[7.0-9.5 \%][32]}\end{array}$ \\
\hline Parainfluenza virus & Single-stranded negative sense RNA. There are four serotypes & $3.1-6.7 \%[31]$ \\
\hline $\begin{array}{l}\text { Human } \\
\text { metapneumovirus }\end{array}$ & Single-stranded negative sense RNA & $<2 \%[32]$ \\
\hline Coronavirus & Single-stranded positive sense RNA virus. There are six serotypes that can infect humans & $0.4-2.7 \%[31]$ \\
\hline Adenovirus & $\begin{array}{l}\text { Double-stranded DNA virus. The species B and C that predominantly cause COPD } \\
\text { exacerbations altogether comprise } 15 \text { serotypes }\end{array}$ & $2.6-5.8 \%[31] ;<2 \%[32]$ \\
\hline
\end{tabular}

Numbers represent mean [96\% confidence interval] 
vaccination against endemic influenza strains is produced on empirical basis, following the outbreaks in South and Far East Asia. Therefore, there is usually a lag time of several months between identification of the virus strain with a potential to cause an influenza endemic, production of the vaccine, and availability of the vaccine for general population and vulnerable subpopulation, including patients with COPD. Due to multiplicity of the human rhinovirus, the virus that causes the majority of upper respiratory viral infections, a universal vaccine has yet to come. Antiviral anti-influenza drugs, such as amantadine, may be effective but have extensive adverse effects [44]. The current guidelines for COPD [11] do not provide recommendations for or against the use of antiviral antiinfluenza drugs. There have been clinical trials on augmentation therapy with aerosolized interferon- $\beta$ in asthma [45]. Interferon- $\beta$ is an antiviral cytokine and may potentially facilitate virus clearance from lower airways of patients with COPD; however, no clinical studies have been done to date to test antiviral efficacy and safety of interferon- $\beta$ in these patients.

With regard to altered microbiome, there is pneumococcal vaccine that boosts immunity against $S$. pneumoni$a e$. This vaccination is currently recommended to all patients with COPD, while there is still a lack of large randomized controlled trials to more objectively assess the benefit of pneumococcal vaccination $[46,47]$. There is also oral vaccine against $H$. influenzae, but the evidence for its efficacy to reduce the number or severity of COPD exacerbations is mixed [48].

The current guidelines for COPD [11] identify three major classes of pharmacological treatment (short-acting bronchodilators, systemic corticosteroids, and antibiotics), along with supporting therapies (oxygen therapy, non-invasive and invasive mechanical ventilation) that are commonly used, with more or less proven efficacy, to curb acute exacerbations of COPD. The guidelines provide stepwise recommendations for the use of pharmacological measures for COPD exacerbations. The guidelines further recommend to follow pharmacological treatment with early outpatient rehabilitation therapy to prevent subsequent exacerbations.

Exacerbations in COPD are often aggravated by comorbidities which are common in these patients (e.g., ischemic heart disease, hypertension, pulmonary hypertension, heart failure, etc.). Therefore, these conditions also require medical attention during treatment of acute exacerbations of COPD. In stable disease, the COPD guidelines recommend to treat co-morbidities as per treatment practices for patients without COPD [11]. There are currently no international guidelines specifically focusing on the management of co-morbidities during COPD exacerbations. It has been noted, though, that COPD exacerbations and co-morbidities appear to influence each other. Thus, patients with COPD and metabolic syndrome, a common co-morbidity in COPD [49], were reported to have more frequent acute exacerbations of COPD [50]. Vice versa, osteoporosis was more severe in patients with COPD who had more frequent exacerbations [51]. Therefore, effective management of co-morbidities in COPD will improve the overall patient well-being and contribute to preventing exacerbations.

\section{Conclusion}

Acute exacerbation of COPD imposes a substantial burden on both the patients and health care system, and leads to increased risk of mortality. Viral infections often precipitate secondary bacterial infections. Both viral and bacterial infections are now recognized as provoking factors of the great majority of acute exacerbations of COPD. Newer therapies are needed to effectively control viral and bacterial infections to prevent COPD exacerbations.

\section{References}

1. Landis, S. H., Muellerova, H., Mannino, D. M., Menezes, A. M., Han, M. K., van der Molen, T., et al. (2014). Continuing to Confront COPD International Patient survey: Methods, COPD prevalence, and disease burden in 2012-2013. International Journal Of Chronic Obstructive Pulmonary Disease, 9, 597-611.

2. Zhong, N., Wang, C., Yao, W., Chen, P., Kang, J., Huang, S., et al. (2007). Prevalence of chronic obstructive pulmonary disease in China: a large, population-based survey. American Journal of Respiratory and Critical Care Medicine, 176, 753-760.

3. Cote, C. G., Dordelly, L. J., \& Celli, B. R. (2007). Impact of COPD exacerbations on patient-centered outcomes. Chest, 131, 696-704.

4. Connors, A. F, Jr., Dawson, N. V., Thomas, C., Harrell, F. E, Jr., Desbiens, N., Fulkerson, W. J., et al. (1996). Outcomes following acute exacerbation of severe chronic obstructive lung disease. The SUPPORT investigators (Study to Understand Prognoses and Preferences for Outcomes and Risks of Treatments). American Journal of Respiratory and Critical Care Medicine, 154, 959-967.

5. Gunen, H., Hacievliyagil, S. S., Kosar, F., Mutlu, L. C., Gulbas, G., Pehlivan, E., et al. (2005). Factors affecting survival of hospitalised patients with COPD. European Respiratory Journal, 26, 234-241.

6. Seemungal, T. A., Donaldson, G. C., Paul, E. A., Bestall, J. C., Jeffries, D. J., \& Wedzicha, J. A. (1998). Effect of exacerbation on quality of life in patients with chronic obstructive pulmonary disease. American Journal of Respiratory and Critical Care Medicine, 157, 1418-1422.

7. Hurst, J. R., Vestbo, J., Anzueto, A., Locantore, N., Mullerova, H., Tal-Singer, R., et al. (2010). Susceptibility to exacerbation in chronic obstructive pulmonary disease. New England Journal of Medicine, 363, 1128-1138. 
8. Soler-Cataluna, J. J., Martinez-Garcia, M. A., Roman Sanchez, P., Salcedo, E., Navarro, M., \& Ochando, R. (2005). Severe acute exacerbations and mortality in patients with chronic obstructive pulmonary disease. Thorax, 60, 925-931.

9. Perera, P. N., Armstrong, E. P., Sherrill, D. L., \& Skrepnek, G. H. (2012). Acute exacerbations of COPD in the United States: inpatient burden and predictors of costs and mortality. Copd: Journal of Chronic Obstructive Pulmonary Disease, 9, 131-141.

10. Chen, Y. H., Yao, W. Z., Cai, B. Q., Wang, H., Deng, X. M., Gao, H. L., et al. (2008). Economic analysis in admitted patients with acute exacerbation of chronic obstructive pulmonary disease. Chinese Medical Journal (English), 121, 587-591.

11. Vestbo, J., Hurd, S. S., Agusti, A. G., Jones, P. W., Vogelmeier, C., Anzueto, A., et al. (2013). Global strategy for the diagnosis, management, and prevention of chronic obstructive pulmonary disease: GOLD executive summary. American Journal of Respiratory and Critical Care Medicine, 187, 347-365.

12. Salvi, S. S., \& Barnes, P. J. (2009). Chronic obstructive pulmonary disease in non-smokers. Lancet, 374, 733-743.

13. Barnes, P. J. (2008). Immunology of asthma and chronic obstructive pulmonary disease. Nature Reviews Immunology, 8, 183-192.

14. Schneider, D., Ganesan, S., Comstock, A. T., Meldrum, C. A., Mahidhara, R., Goldsmith, A. M., et al. (2010). Increased cytokine response of rhinovirus-infected airway epithelial cells in chronic obstructive pulmonary disease. American Journal of Respiratory and Critical Care Medicine, 182, 332-340.

15. Lee, J., Taneja, V., \& Vassallo, R. (2012). Cigarette smoking and inflammation: Cellular and molecular mechanisms. Journal of Dental Research, 91, 142-149.

16. Pappas, R. S. (2011). Toxic elements in tobacco and in cigarette smoke: Inflammation and sensitization. Metallomics, 3, 1181-1198.

17. Pauly, J. L., Smith, L. A., Rickert, M. H., Hutson, A., \& Paszkiewicz, G. M. (2010). Review: Is lung inflammation associated with microbes and microbial toxins in cigarette tobacco smoke? Immunologic Research, 46, 127-136.

18. Fullerton, D. G., Bruce, N., \& Gordon, S. B. (2008). Indoor air pollution from biomass fuel smoke is a major health concern in the developing world. Transactions of the Royal Society of Tropical Medicine and Hygiene, 102, 843-851.

19. Naeher, L. P., Brauer, M., Lipsett, M., Zelikoff, J. T., Simpson, C. D., Koenig, J. Q., \& Smith, K. R. (2007). Woodsmoke health effects: A review. Inhalation Toxicology, 19, 67-106.

20. Mehra, D., Geraghty, P. M., Hardigan, A. A., \& Foronjy, R. (2012). A comparison of the inflammatory and proteolytic effects of dung biomass and cigarette smoke exposure in the lung. PLoS One, 7, e52889.

21. Danielsen, P. H., Moller, P., Jensen, K. A., Sharma, A. K., Wallin, H., Bossi, R., et al. (2011). Oxidative stress, DNA damage, and inflammation induced by ambient air and wood smoke particulate matter in human A549 and THP-1 cell lines. Chemical Research in Toxicology, 24, 168-184.

22. Barnes, P. J. (2014). Cellular and molecular mechanisms of chronic obstructive pulmonary disease. Clinics in Chest Medicine, 35, 71-86.

23. Sze, M. A., Hogg, J. C., \& Sin, D. D. (2014). Bacterial microbiome of lungs in COPD. International Journal of Chronic Obstructive Pulmonary Disease, 9, 229-238.

24. Barker, B. L., \& Brightling, C. E. (2013). Phenotyping the heterogeneity of chronic obstructive pulmonary disease. Clinical Science (London), 124, 371-387.

25. Celli, B. R., Halbert, R. J., Nordyke, R. J., \& Schau, B. (2005). Airway obstruction in never smokers: results from the Third National Health and Nutrition Examination Survey. The American Journal of Medicine, 118, 1364-1372.
26. Lamprecht, B., McBurnie, M. A., Vollmer, W. M., Gudmundsson, G., Welte, T., Nizankowska-Mogilnicka, E., et al. (2011). COPD in never smokers: results from the populationbased burden of obstructive lung disease study. Chest, 139, $752-763$.

27. Behrendt, C. E. (2005). Mild and moderate-to-severe COPD in nonsmokers: Distinct demographic profiles. Chest, 128, 1239-1244.

28. Huang, Y. J., Sethi, S., Murphy, T., Nariya, S., Boushey, H. A., \& Lynch, S. V. (2014). Airway microbiome dynamics in exacerbations of chronic obstructive pulmonary disease. Journal of Clinical Microbiology, 52, 2813-2823.

29. Stockley, R. A., O’Brien, C., Pye, A., \& Hill, S. L. (2000). Relationship of sputum color to nature and outpatient management of acute exacerbations of COPD. Chest, 117, 1638-1645.

30. Sethi, S., Wrona, C., Grant, B. J., \& Murphy, T. F. (2004). Strainspecific immune response to Haemophilus influenzae in chronic obstructive pulmonary disease. American Journal of Respiratory and Critical Care Medicine, 169, 448-453.

31. Zwaans, W. A., Mallia, P., van Winden, M. E., \& Rohde, G. G. (2014). The relevance of respiratory viral infections in the exacerbations of chronic obstructive pulmonary disease-A systematic review. Journal of Clinical Virology, 61, 181-188.

32. Wu, X., Chen, D., Gu, X., Su, X., Song, Y., \& Shi, Y. (2014). Prevalence and risk of viral infection in patients with acute exacerbation of chronic obstructive pulmonary disease: A metaanalysis. Molecular Biology Reports, 41, 4743-4751.

33. Molyneaux, P. L., Mallia, P., Cox, M. J., Footitt, J., Willis-Owen, S. A., Homola, D., et al. (2013). Outgrowth of the bacterial airway microbiome after rhinovirus exacerbation of chronic obstructive pulmonary disease. American Journal of Respiratory and Critical Care Medicine, 188, 1224-1231.

34. Chhabra, S. K., \& Dash, D. J. (2014). Acute exacerbations of chronic obstructive pulmonary disease: Causes and impacts. Indian Journal of Chest Diseases and Allied Sciences, 56, 93-104.

35. Kurai, D., Saraya, T., Ishii, H., \& Takizawa, H. (2013). Virusinduced exacerbations in asthma and COPD. Frontiers in Microbiology, 4, 293.

36. Sajjan, U. S. (2013). Susceptibility to viral infections in chronic obstructive pulmonary disease: Role of epithelial cells. Current Opinion in Pulmonary Medicine, 19, 125-132.

37. Gunawardana, N., Finney, L., Johnston, S. L., \& Mallia, P. (2014). Experimental rhinovirus infection in COPD: implications for antiviral therapies. Antiviral Research, 102, 95-105.

38. Mackay, A. J., \& Hurst, J. R. (2012). COPD exacerbations: Causes, prevention, and treatment. Medical Clinics of North America, 96, 789-809.

39. Mallia, P., Footitt, J., Sotero, R., Jepson, A., Contoli, M., TrujilloTorralbo, M. B., et al. (2012). Rhinovirus infection induces degradation of antimicrobial peptides and secondary bacterial infection in chronic obstructive pulmonary disease. American Journal of Respiratory and Critical Care Medicine, 186, $1117-1124$

40. Jenkins, C. R., Celli, B., Anderson, J. A., Ferguson, G. T., Jones, P. W., Vestbo, J., et al. (2012). Seasonality and determinants of moderate and severe COPD exacerbations in the TORCH study. European Respiratory Journal, 39, 38-45.

41. Miravitlles, M., Ferrer, M., Pont, A., Zalacain, R., Alvarez-Sala, J. L., Masa, F., et al. (2004). Effect of exacerbations on quality of life in patients with chronic obstructive pulmonary disease: A 2 year follow up study. Thorax, 59, 387-395.

42. Eccles, R. (2002). An explanation for the seasonality of acute upper respiratory tract viral infections. Acta Oto-Laryngologica, 122, 183-191.

43. Wisniewski, D., Porzezinska, M., Gruchala-Niedoszytko, M., Niedoszytko, M., Slominski, J. M., \& Jassem, E. (2014). Factors 
influencing adherence to treatment in COPD patients and its relationship with disease exacerbations. Pneumonologia $i$ Alergologia Polska, 82, 96-104.

44. van der Wouden, J. C., Bueving, H. J., \& Poole, P. (2005). Preventing influenza: An overview of systematic reviews. Respiratory Medicine, 99, 1341-1349.

45. Djukanovic, R., Harrison, T., Johnston, S. L., Gabbay, F., Wark, P., Thomson, N. C., et al. (2014). The effect of inhaled IFN-beta on worsening of asthma symptoms caused by viral infections. A randomized trial. American Journal of Respiratory and Critical Care Medicine, 190, 145-154.

46. Varkey, J. B., Varkey, A. B., \& Varkey, B. (2009). Prophylactic vaccinations in chronic obstructive pulmonary disease: Current status. Current Opinion in Pulmonary Medicine, 15, 90-99.

47. Walters, J. A., Smith, S., Poole, P., Granger, R. H., \& WoodBaker, R. (2010). Injectable vaccines for preventing pneumococcal infection in patients with chronic obstructive pulmonary disease. Cochrane Database Systematic Review. doi:10.1002/ 14651858.

48. Teo, E., House, H., Lockhart, K., Purchuri, S. N., Pushparajah, J., Cripps, A. W., \& van Driel, M. L. (2014). Haemophilus influenzae oral vaccination for preventing acute exacerbations of chronic bronchitis and chronic obstructive pulmonary disease. Cochrane Database Systematic Review, 9, Cd010010.

49. Agusti, A., \& Soriano, J. B. (2008). COPD as a systemic disease. Copd: Journal of Chronic Obstructive Pulmonary Disease, 5, 133-138.
50. Kupeli, E., Ulubay, G., Ulasli, S. S., Sahin, T., Erayman, Z., \& Gursoy, A. (2010). Metabolic syndrome is associated with increased risk of acute exacerbation of COPD: A preliminary study. Endocrine, 38, 76-82.

51. Kiyokawa, H., Muro, S., Oguma, T., Sato, S., Tanabe, N., Takahashi, T., et al. (2012). Impact of COPD exacerbations on osteoporosis assessed by chest CT scan. Copd: Journal of Chronic Obstructive Pulmonary Disease, 9, 235-242.

52. Park, H., Shin, J. W., Park, S. G., \& Kim, W. (2014). Microbial communities in the upper respiratory tract of patients with asthma and chronic obstructive pulmonary disease. PLoS One, 9, e109710.

53. Zakharkina, T., Heinzel, E., Koczulla, R. A., Greulich, T., Rentz, K., Pauling, J. K., et al. (2013). Analysis of the airway microbiota of healthy individuals and patients with chronic obstructive pulmonary disease by T-RFLP and clone sequencing. PLoS One, 8 , e68302.

54. Cabrera-Rubio, R., Garcia-Nunez, M., Seto, L., Anto, J. M., Moya, A., Monso, E., \& Mira, A. (2012). Microbiome diversity in the bronchial tracts of patients with chronic obstructive pulmonary disease. Journal of Clinical Microbiology, 50, 3562-3568.

55. Huang, Y. J., Kim, E., Cox, M. J., Brodie, E. L., Brown, R., Wiener-Kronish, J. P., \& Lynch, S. V. (2010). A persistent and diverse airway microbiota present during chronic obstructive pulmonary disease exacerbations. OMICS: A Journal of Integrative Biology, 14, 9-59. 